\title{
Cost-benefit analysis of BIM-enabled design clash detection \& resolution
}

Racha Chahrour ${ }^{1}$, Mian Atif Hafeez ${ }^{2}$, Ahmad Mohammad Ahmad ${ }^{3}$, Hashim Ibnauf Sulieman ${ }^{4}$, Huda Dawood $^{2}$, Sergio Rodriguez-Trejo ${ }^{2}$, Mohamad Kassem ${ }^{5}$, Khalid Kamal Naji ${ }^{3}$, Nashwan Dawood $^{2 *}$

${ }^{1}$ HOCHTIEF ViCon, Germany

${ }^{2}$ Teesside University, UK

${ }^{3}$ Qatar University, Doha, Qatar

${ }^{4}$ Ministry of Infrastructure and Transportation, Government of Sudan, Khartoum, Sudan

${ }^{5}$ Dept of Mechanical and Construction Engineering, Northumbria University, UK

*Corresponding Author: N.N.Dawood@tees.ac.uk, School of Computing, Engineering \& Digital Technologies, Teesside University, Middlesbrough, UK

\section{Abstract}

Building Information Modelling (BIM) is increasingly deployed as part of the processes in Architecture, Engineering and Construction (AEC) industry projects. While the benefits of BIM have been extensively proclaimed, explicit justification in terms of direct cost savings for BIM implementation on real-life projects, particularly for clash detection BIM workstream, are not well documented. This paper proposes and demonstrates a methodology to prove how BIM-based clash detection leads to cost savings. A schema is developed based on literature review and industrial expertise to quantify cost savings achieved by the utilisation of BIM-based clash detection and resolution. This paper provides validation of the proposed schema on a major infrastructure project. The developed schema includes the categorisation of identified clashes based on stakeholder involvement and required actions. The validation used the estimated cost of clashes were those not resolved before site operations took place. This schema simplifies both the categorisation and cost estimation of clashes in design. Estimated savings yielded $20 \%$ of contract value using the schema, for the multi-million-dollar project case study, thus extending evidence of BIM savings and benefits. The schema improves the existing process and valorises clash detection, thus allowing stakeholders to conduct a cost-benefit analysis. In addition, the categorisation methodology allows prioritising on the most costly clashes, and draw lessons learnt for further projects. This schema opens the path towards a systematic methodology to appraise the benefits of different BIM uses or processes. 
Keywords: Building Information Modelling (BIM), Cost Estimation, Clash detection, BIM Savings, BIM Case Study, Cost benefit analysis

\section{Introduction}

The construction industry is lagging behind other industries when it comes to efficiency, productivity, collaboration, and standardization. According to the Office for National Statistics (2019), construction labour productivity measured by output per hour fell by $4.8 \%$ in Q4 2018 compared to Q4 2017 in the UK. The report showed that labour productivity/hr stagnates at around $£ 26 / \mathrm{hr}$ compared to manufacturing at around $£ 40 / \mathrm{hr}$ (Office for National Statistics, 2019). Building Information Modelling (BIM), Digital construction and collaborative project delivery are deemed to have a positive impact on construction productivity and improvement in the built environment. While research and industry have argued the potential benefits of using BIM (Barlish and Sullivan, 2012; Jin et al., 2017; Zhang et al., 2018) the perceived economic benefits are often ambiguous and intangible and therefore considered as a key obstacle in BIM adoption (Papadonikolaki and Aibinu, 2017; Tan et al., 2019).

Even after the recent push to adopt BIM in the UK, driven by mandate and standards, e.g. BS 1192:2007, PAS 1192-2:2013 and PAS 1192-3:2016, (BSI, 2007, 2013, 2014), and followed by other initiatives in Western countries, e.g. ISO-EN 19650:2018 (ISO, 2018), potential barriers to BIM implementation still exist, e.g. cost of implementation and lack of hard evidence of the benefits of BIM (PwC, 2018a, p. 3). This reiterates the need for further BIM adoption studies that link costs and benefits.

The evaluation of the value of different BIM workstreams in the AEC industry is still unsolved. PriceWaterhouseCoopers (PwC, 2018a) reports that the lack of information needed for a quantitative assessment prevents an accurate quantification of the BIM benefits. Though acknowledging the possibility of quantifying clash detection and resolution, some stakeholders 
discard it adducing it would be resource-intensive and would not be systematically adopted from early project stages (ibid.). A simplified methodology to appraise the value that BIM processes add to the client would push the adoption of this technical advantage.

As stated by Baldwin et al. (1999), the study of schemata in current process flows results in effective process improvement or adding steps to advantage certain aspects of the processes. Theirs research was based on consultation with stakeholders at different stages and used several case studies. Focused on the conceptual and schematic design stages, it delivered schemata and data-flow diagrams with the changes needed to improve the information flow in current architectural and engineering major infrastructure works.

Savings are paramount for BIM adoption, however rarely estimated due to lack of data and proper analysis techniques. As a result, cost-benefit analyses are frequently either underestimated or exaggerated. As stated by Chan et al. (2019), lack of certainty in assessing BIM impact on cost and waste remains on multiple occasions as a significant barrier to BIM implementation. Moreover, according to this research, the main benefits of implementing BIM relate to cost-control and design, i.e. reduced errors, or in other words, resolved clashes.

This paper aims to develop a simplified schema enabling construction stakeholders to conduct a cost-benefit analysis of BIM-enabled clash detection. This schema was developed through interviews with industry experts. It was then validated in a major industrial infrastructure case study. The case study encompassed the coordination among disciplines at the interface of two projects: project A, a rail tunnel infrastructure; and project B, a boulevard street with underground car park facilities, roads and utilities. Penn State process maps (Saluja, 2009; Messner et al., 2019) were used as a reference for the BIM-enabled clash detection business process map. 
Both projects were contracted according to Design-Bid-Build project-delivery procurement route. Two steps were considered within the case study; step 1) BIM based clash detection: and step 2) cost assessment for the identified clashes. These were explored in the case study through two dedicated workshops. The design and coordination processes were initiated in 2D drawings. The initial models were 3D modelled based on the 2D drawings and coordinated for clash detection. The BIM based clash detection allows digital and collaborative effort prior to the actual construction; BIM teams detected and resolved a number of hidden conflicts within the discipline models and clearly uncovered significant limitations in 2D drawings in comparison to the rich $3 \mathrm{D}$ models. These saved costs for additional procurement, demolitions, further works caused by redesign and significant interruptions to project schedule. Moreover, the ability to visualise a comprehensive consolidated model not only allowed pre-construction clash detections, but also enabled making informed decisions to resolve the conflicts with the least rework needed. The cost implications of clashes are calculated as if the clashes remained undetected during design, and were resolved using real cost data from the project case study.

The subsequent sections present: a) literature review on clash detection and quantification of cost savings achieved; b) research methodology; c) schema development; d) Case study covering major, medium, and minor categories of clashes and the estimate of their cost impact; followed by e) discussion; and f) conclusions.

\section{Literature Review}

$\mathrm{BIM}$ is considered to be a technology-enabled process that allows the production, management and exchange of digital data throughout the lifecycle of a building or infrastructure project (Sacks et al., 2018). Effective collaboration (leading to Clash avoidance) and coordination (leading to Clash detection and Resolution) are key processes of the overall design coordination, but BIM implementation is not absent of hurdles. Studies and research, such as of 
PriceWaterHouse (PwC, 2018a) and Becerik-Gerber and Rice (2010), stated the various challenges to developing methodologies that facilitate quantification of clash detection within a BIM-enabled project. This paper focuses on methodologies to categorise and quantify clashes, and appraisal of savings achieved through adopting an improved clash detection schema.

\section{Clash detection}

Clashes can be described as waste in the production system (Tommelein and Gholami, 2012). Clash detection is one of many quality checks conducted by designers before they release their models for further downstream delivery processes. Furthermore, they stated that clashes could be described as an error or omission that can be resolved by designers, modellers, and constructors with an interdisciplinary discussion. Project clashes root on Design uncertainty, e.g. a designer put a placeholder in place of a component for a later resolution; Failing of design rules, i.e. lack of agreement that could avoid space component clashes from different design disciplines; Model accuracy and tolerance, e.g. tolerating model inaccuracy due to set deadlines to be resolved at a later stage; and Design errors, e.g. these could be dimensions or location errors leading to clashes.

Design coordination process results in early detection of these clashes (Kreider and Messner, 2013), and hence a reduction in conflicts during construction which is more costly. It is of such an importance, that some research suggests that progress to construction stage should not take place without a coordinated design agreement within relevant stakeholders involved in a project (Riley and Horman, 2001). Clash detection is one of the most applied BIM uses in the construction industry (Eadie et al., 2013). Wang (2014) described effective clash detection as an iterative process in which project conflicts are periodically identified, classified, evaluated and resolved until a coordinated model with minimal or acceptable clashes is observed. The underlying problem becomes the lack of formalised experiential knowledge, this meaning that 
lessons learnt analysis on resolved clashes is seldom conducted. Another unresolved aspect is the number of false positives, which amount to $50 \%$ and poses a risk to the effective design coordination.

Although some authors see concurrent design as leading to a greater number of defects (Handfield, 1994), recent research from Akponeware and Adamu (2017) suggests that modern collaboration in BIM-enabled environment could benefit from a co-creation, and proposed a conceptual framework for an open work in progress (OWIP) to address promptly a number of clashes, early detected and resolved, and hence reducing the number of iterations needed to achieve a clash-free model. While this is an inspiring way of avoiding clashes, current practice in the industry mostly develops silo-based discipline models before any coordination or clash detection is conducted (Berdeja, 2014).

A survey conducted by McGraw-Hill Construction (2012) showed that both clash avoidance and clash detection are frequently implemented BIM Uses in the industry, leading to immediate benefits and furthermore, other studies have shown that design coordination and conflict detection are the most frequent and valued uses of BIM in the construction sector (Bernstein and Jones, 2012). However, there is still a gap in the classification of clashes and the quantification of the benefits.

There have been a number of attempts to categorise clashes. Han et al. (2012) approached classification in three levels of impact severity, i.e. interruption, productivity loss (such as causing a request for information or change order) and rework. Wang and Leite (2016) built a knowledge management schema for clash management and proposed a prototype system to show how knowledge can be captured. This theoretical framework is difficult to be implemented in the construction industry given that every project and company have their own unique environment. The schema proposed is constrained to clash representation and not for determination of benefits 
of clash detection, unlike the one described in this paper, which allows determination of benefits from implementation of coordination processes, one of the novelties in this research.

Clash classification is found in the literature in varied forms, but commonly, the different approaches refer to impact severity and delay related to the clashes. Staub-French and Khanzode (2007) described soft clashes as interference between physical components and clearance space', while hard clashes are defined as 'interference between components'. Han et al. (2012) classified clashes into three types according to the severity of its impact causing; interruption; productivity loss (such as causing a request for information or change order); and rework. Wang (2014), in a similar approach, categorized clashes according to their impact severity as high) lead to cost overruns and schedule delays need immediate attention; medium) impact on cost and schedule and need to be resolved before construction; and low) minimum impact on cost and schedule that can be resolved on site.

Riley et al. (2005) discussed the process of coordination using 2D CAD rather than clash detection using BIM processes. Certain types of Coordination Conflicts, Timing of Detection, and Severity of Impact were discussed, and certain aspects of the classification was used to provide background context in the paper. Aspects of time of coordination and severity, which in MEP discipline usually leads to a major clash were highlighted in Riley et al. (2005). These are time of detection (Project stage) and severity of impact of clash. Time of clash detection is categorised into three, i.e. detected and resolved before installation begun (type 1); detected after trade one has completed work and trade two rerouting pipes (type 2); detected after trade one has completed work, while trade two has to wait (type 3). While severity of impact is also categorised into three. These are: start of work delayed, redesign required (type 1); Trade two disrupted and potential redesign and fabrication changes required (type 2); trade one disrupted, redesign and rework required, trade 2 delayed (type 3 ). The paper introduced different costing 
scenarios of MEP coordination and was based on subjective inputs from foremen and construction managers. The proposed schema in this paper adopts a different approach to categorise clashes, provides detailed and real case-study based cost estimation of clashes in case they were not detected before construction, and the actual cost of conducting clash detection.

Tommelein and Gholami (2012) described three types of clashes as: hard clashes, that lead to physical clashes of building components of the different discipline elements; soft clashes, understood as clearance clashes. These occur when systems or subsystems are closer to each other within a defined set distance; and time clashes, when two or more building elements occupying the same space at the same period during construction or operation of the facility. This is modelled as a temporary clearance requirement. Parn et al. (2018) suggest another type which is duplicate clashes i.e. multiple versions of the same 'singular clash' that are repeated throughout a building (e.g. an MEP pipe that travels along the entire length of a structural column will be observed and recorded numerous times even though it actually represents one error). The duplicated clashes are usually resolved through grouping them into different categories (Pärn, Edwards and Sing, 2018).

Table 1 summarises clash detection considerations with regards to stakeholders involved, impact severity, disciplines affected by the resolution. 
Table 1: Summary of clash detection review

\begin{tabular}{|c|c|c|}
\hline Clash consideration & Description & Reference \\
\hline Clash categorisation & $\begin{array}{l}\text { Major (hard), average and } \\
\text { minor (soft) }\end{array}$ & $\begin{array}{l}\text { Messner et al. (2019) } \\
\text { Staub-French and } \\
\text { Khanzode (2007) } \\
\text { Riley and Horman } \\
\text { (2001) } \\
\text { Gijezen et al., (2010) } \\
\text { Tommelein and } \\
\text { Gholami (2012) } \\
\text { Parn et al. (2018) }\end{array}$ \\
\hline Clash stakeholders & $\begin{array}{l}\text { Client, consultants, } \\
\text { contractors }\end{array}$ & $\begin{array}{l}\text { Staub-French and } \\
\text { Khanzode (2007) } \\
\text { PwC (2018a, 2018b) }\end{array}$ \\
\hline Clash application & Manual and automated & $\begin{array}{l}\text { Staub-French and } \\
\text { Khanzode (2007) }\end{array}$ \\
\hline $\begin{array}{l}\text { Stakeholder involvement } \\
\text { in defining clashes }\end{array}$ & $\begin{array}{l}\text { Define clashes based on } \\
\text { stakeholders' involvement } \\
\text { during the resolution } \\
\text { process }\end{array}$ & Gijezen et al., (2010) \\
\hline $\begin{array}{l}\text { Clash resolution } \\
\text { assumptions }\end{array}$ & $\begin{array}{l}\text { Percentage of avoided costs } \\
\text { through conventional clash } \\
\text { resolution approaches. } \\
\text { These are: }\end{array}$ & \\
\hline
\end{tabular}




\begin{tabular}{|l|l|l|}
\hline & $\bullet 75 \%$ & Neelamkavil and \\
& Ahamed (2012) \\
& Azhar et al. (2012) \\
\hline
\end{tabular}

\section{Challenges regarding Clash Detection}

One of the current challenges referred to Clash detection relates to identification and classification. Within complex projects, it is difficult to identify relevant clashes. This makes coordination more complex and resource consuming (Ashcraft, 2008). The use of clash detection software solutions lead to generation of a high number of clashes, some of which might not be relevant or important, but result in time and resources to sort out (Hartmann, 2010). In its 2012 SmartMarket report, McGraw-Hill (2012) stated that the process of calculation is difficult or cumbersome due to factors such as cost, system and staffing required for managing the activities involved. Leite et al. (2011) also highlighted the need to filter irrelevant clashes when investigating clash detection results. Hu and Castro-Lacouture (2019) described that clash management processes can be improved by automatically distinguishing between relevant and irrelevant clashes. This will result in time saving and will allow project team members to focus on relevant clashes only. This automated classification system would theoretically simplify the quantification process. To achieve a clear and simplified methodology, the process of categorisation and generalisation is proposed in this study, which could make use of the proposed approach by $\mathrm{Hu}$ and Castro-Lacouture.

Wang (2014) also stated that previous studies have not presented a structure to represent clash information. A documentation method should allow quantification of the clashes through a structured methodology for future reference. Mehrbod et al. (2019) observed clash detection issues 
to include repeated clashes (physical), multiple system conflicts and design error (process), and missing information (model). In the study conducted, they found that 'the most common design coordination issue across both case studies was design error. The temporal and functional design issues took the longest time to resolve and missing information took the least amount of time. Design discrepancies were least likely to be resolved by the end of design coordination.'

Guangbin et al. (2011) recommend clash detection to be conducted not just after design before construction, but at the early and even in ulterior stages. BIM-based clash detection is becoming more crucial in early design stages and plays an ever major role throughout the design process to design production (Seo et al., 2012).

Korman et al. (2003) on the other hand argued that clash detection encourages practitioners to make mistakes, in the belief that they would be detected at a later stage. One of the challenges of performing early clash detection is the lack of detailed information, leading to some of the building components not being modelled adequately. Therefore, some practitioners do not address possible clashes during the design stage.

In his article, Wang (2014) indicated that research challenges associated with design coordination include 1) Inadequate documentation and format (identify what needs to be documented with appropriate format); 2) Insufficient management of documented clash information (should be linked to the model); and 3) Loss of experiential knowledge (add how clashes are resolved to documentation rather than only the clash viewpoint and clash documents/ $\log )$.

Further challenges of the previous studies on quantification of clash detection include the estimation of stakeholder engagement towards quantification of benefits within a given project; stakeholder time constraints; stakeholder hesitance and capacity to quantify BIM benefit; Supply chain being reluctant to report benefits; commercially sensitive data hindering analysis; 
commercial tension between client and suppliers, etc (PwC, 2018b). Others include the limitation of grouping strategy, since clashes are listed in specific floor levels rather than to tolerances (hard/soft clashes) or to their impact on the construction process.

\section{Quantification of Clash detection}

Becerik-Gerber and Rice (2010) described that one of the reasons for lack of BIM implementation is the inadequate number of projects showing successful and consistent cost savings and positive ROI. Clash detection can lead to fewer changes, reduced cost of warranty claim, time to address errors, time spent in; developing design; documenting; coordinating change orders and rework; responding to RFIs; and for redesign on field (Hoffer, 2016). McGraw Hill SmartMarket Report (2009) showed an increase in figures for BIM ROI (Young et al., 2009), whilst Becerik-Gerber and Rice (2010) indicated a reduction. Latiffi and Tai (2019) suggested that reduction in figures is due to steep learning curve and preliminary cost during early implementation stages. However, they stated that most of the savings in a BIM project are achieved due to clash detection. McGraw-Hill (2009) indicated that clash detection has the highest ROI among the BIM uses, because of reducing costly change orders (Young et al., 2009). The SmartMarket Report (Bernstein and Jones, 2012) stated the value of BIM ROI could influence decision making to implement BIM. They further stated that 'Calculating ROI has become a necessary evaluation step prior to many capital or labour-intensive business investments, such as BIM adoption. Currently there is no industry standard method for BIM ROI'. Furthermore, ROI estimates of BIM are questionable due to the perception based methodologies adopted, and lack of standard methods to estimate ROI (Bernstein and Jones, 2012).

In their report, PwC (2018b) provided a high-level methodology for quantifying BIM level 2 maturity. They identify eight categories of benefits. These include time saving, material 
savings, cost savings, risk reduction, health and safety improvement, asset utilization, asset quality and improved reputation. Four benefit estimates are quantifiable; these are future cost savings in asset maintenance, time saving in design, build and commissioning, and cost savings from clash detection. However, a detail method on quantifying clash detection is not presented.

Quantification of clash detection, however challenging, enable clients to visualise possible savings. ROI by using BIM for clash detection can be achieved through estimates of staff-hours and material cost that would be required if clash was not detected through automated clash detection (Giel and Issa, 2013). Azhar et al. (2012) stated that one of BIM benefits is to enable error identification through the Clash detection process, hence reducing uncertainty of production processes in building construction projects.

Leite et al. (2011) stated that a simple listing of clashes does not necessarily improve the data consistency of one process or project, hence further classification categories, Recall and precision, were defined. Recall refers to completeness of clashes (ratio of true positives to number of clashes that should have been identified) while precision refers to the exactness of clashes (ratio of true number positives to total retrieved clashes). Recall and precision are inversely proportional. The study indicated that an increase in recall could lead to an increase in false positives, while decreasing precision.

Bockstael and Issa (2016) developed a methodology to find ROI based on Giel and Issa (2013). It also allowed the identification of the failure mode and effect analysis, recommending corrective actions to resolve clashes. However, the process would be time consuming and more complex due to the additional identification of cause of each clash and recommendation for each correction. In cases with thousands of clashes, this method becomes time consuming. However, if managed adequately, it would add value and help stakeholders to make informed decision at later stages or alternative projects. 
Azhar et al. (2012) illustrated a case study where a number of clashes were recorded and aligned with the different levels within a construction project. The estimated cost avoided and total crew hours were stated with coordination dates. A $15 \%$ material factor was added while an assumed $33 \%$ of total cost could be avoided through conventional/ traditional methods. In a study conducted by Riley and Horman (2001), an effort to quantify the cost of investment in the coordination process was conducted. Four sets of data were collected. These include: 1) Coordination effort, the effort required to achieve the removal of physical interference that could hinder project progress; 2) Field conflicts, issues that could have been detected during the coordination process. These are the virtual clashes recorded during clash detection; 3) coordination costs, the cost of the coordination process adopted within a given project; and 4) conflict costs, average cost of field conflicts that were not detected during the design coordination process and the implication of adopting any defined delivery system.

A study was conducted by Neelamkavil and Ahamed (2012) in which construction conflicts (MEP collisions) recorded in fifteen different floors were analysed. Quantification required the collection of the following: Number of collisions per floor; estimated cost of avoided collision per floor; estimated crew hours and the coordination date. MEP material values was set $20 \%$ while a $75 \%$ deduction was assumed for resolution through conventional/ traditional methods. Neelamkavil and Ahamed (2012) and Azhar (2012) adopted a similar strategy of quantification per level. The quantification process implies that a 100-floor building would need a long process to quantify. Collision per level, Cost avoided per level, estimated crew hours per level, all need to be quantified. In addition, there are different deductions due to assumed resolution through conventional methods, which has a large range of (75\% and 33\%) respectively. This is effective to make deductions, as there are potential cost savings using manual 2D drawings based clash detection. The challenge with this approach is that when clash 
detection is conducted during construction, it implies that traditional clash detection has finished in earlier stages. As a result, the deduction would not apply, as design coordination is complete.

The table 2 below provides relevant studies in the field of clash detection with the proposed quantification schema. The authors have adopted strategies of categorising clashes, identifying timing of clash detection during coordination and method of filtering the false positives. The proposed approach fills the gaps detected in the literature review, by simplifying and establishing assumptions based on expert opinion, which can be extrapolated to other cases. A generalisation of cases is useful in establishing main roots for clashes. It also helps in the estimate of the relevant clashes VS false positives, although for this aim, automated filtering can be applied. In the proposed approach, manual determination is conducted, and escalation is applied. The categorisation of the impact severity, as well as the generalisation of cases, helps in the quantification process.

Table 2: Quantification of clash detection in literature

\begin{tabular}{|c|c|c|c|c|c|c|}
\hline References & $\begin{array}{l}\text { Quantification } \\
\text { strategy- Description }\end{array}$ & $\begin{array}{l}\text { Quantification } \\
\text { process } \\
\text { presented }\end{array}$ & $\begin{array}{l}\text { Allow } \\
\text { quantification } \\
\text { of all clash } \\
\text { categories }\end{array}$ & $\begin{array}{l}\text { Filter False } \\
\text { positives and } \\
\text { check for } \\
\text { false } \\
\text { negatives }\end{array}$ & $\begin{array}{l}\text { Generalization of } \\
\text { clashes in each } \\
\text { category }\end{array}$ & $\begin{array}{l}\text { Simplifie } \\
\text { d }\end{array}$ \\
\hline $\begin{array}{l}\text { Neelamkavil } \\
\text { and Ahamed, } \\
\text { (2012). }\end{array}$ & $\begin{array}{l}\text { Clashes were } \\
\text { considered per levels. } \\
\text { MEP material values } \\
\text { was assigned } 20 \% \\
\text { while a } 75 \% \\
\text { deduction was } \\
\text { assumed for } \\
\text { resolution through } \\
\text { conventional }\end{array}$ & $\mathrm{X}$ & $\mathrm{X}$ & NA & NA & NA \\
\hline
\end{tabular}




\begin{tabular}{|c|c|c|c|c|c|c|}
\hline & $\begin{array}{l}\text { methods. (conducted } \\
\text { case study) }\end{array}$ & & & & & \\
\hline $\begin{array}{l}\text { Azhar et al., } \\
\text { (2012). }\end{array}$ & $\begin{array}{l}\text { Clashes were } \\
\text { considered per levels. } \\
15 \% \text { material factor } \\
\text { was added while an } \\
\text { assumed } 33 \% \text { of cost } \\
\text { total could be avoided } \\
\text { through conventional } \\
\text { methods. } \\
\text { (conducted case } \\
\text { study) }\end{array}$ & $\mathrm{X}$ & $\mathrm{X}$ & NA & NA & NA \\
\hline $\begin{array}{l}\text { Riley et al., } \\
\text { (2005). }\end{array}$ & $\begin{array}{l}\text { MEP clash cost per } \\
\text { square feet analogy. } \\
\text { This method excludes } \\
\text { other clashes } \\
\text { categories from other } \\
\text { relevant stakeholders. } \\
\text { They did not consider } \\
\text { savings due to } \\
\text { traditional clash } \\
\text { detection. (conducted } \\
\text { surveys) }\end{array}$ & $\mathrm{X}$ & NA & NA & NA & NA \\
\hline $\begin{array}{l}\text { Althizer, } \\
\text { (2016). }\end{array}$ & $\begin{array}{l}\text { AIA/ AGC proposed } \\
\text { an average of } \$ 1500 / \\
\text { per instance of a } \\
\text { significant clash. } \\
\text { Other clash categories } \\
\text { need to be quantified. } \\
\text { They did not consider } \\
\text { savings due to }\end{array}$ & $\mathrm{X}$ & NA & NA & $\mathrm{X}$ & $\mathrm{X}$ \\
\hline
\end{tabular}




\begin{tabular}{|l|l|l|l|l|l|l|}
\hline & $\begin{array}{l}\text { traditional clash } \\
\text { detection }\end{array}$ & & & & \\
\hline Leite et al., & $\begin{array}{l}\text { Identified the strategy } \\
\text { to count the clashes } \\
\text { that will enable the } \\
\text { quantification } \\
\text { process. A method for } \\
\text { the quantification of } \\
\text { the clashes was not } \\
\text { presented (Case study } \\
\text { was conducted) }\end{array}$ & NA & X & NA & & \\
paper & $\begin{array}{l}\text { Quantification is } \\
\text { conducted per clash } \\
\text { covering clashes from } \\
\text { all categories. clashes } \\
\text { are categorised and } \\
\text { generalised to be } \\
\text { multiplied by a } \\
\text { category average to } \\
\text { save time towards } \\
\text { cost quantification. } \\
\text { (case study was } \\
\text { conducted) }\end{array}$ & $\mathrm{X}$ & $\mathrm{X}$ & & & \\
\hline Authors & & & & & & \\
\hline
\end{tabular}




\section{Research Methodology}

The paper follows a qualitative and inductive research methodology to develop and validate a schema based on experts' observations, interviews and case study (Blaikie, 2009; Yin, 2009; Pope and Mays, 2013; Bryman, 2016). The exercise of determining a process improvement by adopting a data flow analysis developed by Baldwin et al. (1999) can be also considered a precursor of the methodology used in this research. Similarly to the approach in the latter, to develop the schema for the quantification of clash detection, best practices from industry experts (BIM managers and coordinators/ designers and project managers) were incorporated using interviews. The interviewees are described in Table 3, each having a minimum of 5 years of BIM related experience. The schema was validated through case study on a real-life project. Case study participants are described in Table 4. Previous studies quantifying cost savings through clash detection used the case study method to verify their work as well (Leite et al., 2011; Azhar, Khalfan and Maqsood, 2012; Neelamkavil and Ahamed, 2012).

Table 3. List of interviewees

\begin{tabular}{|l|l|l|}
\hline $\begin{array}{l}\text { Organisation } \\
\text { type }\end{array}$ & $\begin{array}{l}\text { Job title of } \\
\text { interviewees }\end{array}$ & Interview \\
\hline Designer & BIM Manager & 1 \\
BIM Manager & 1 \\
\hline $\begin{array}{l}\text { Cost } \\
\text { Surveyor }\end{array}$ & $\begin{array}{l}\text { BIM Manager } \\
\text { and Senior } \\
\text { QS }\end{array}$ & 1 \\
\hline Contractor & Vice president & 1 \\
\hline $\begin{array}{l}\text { BIM } \\
\text { Consultant } \\
\text { /Technology } \\
\text { Partner }\end{array}$ & $\begin{array}{l}\text { Project } \\
\text { Consultant }\end{array}$ & 1 \\
\hline
\end{tabular}


Table 4. List of participants in the case study workshops

\begin{tabular}{|c|c|c|c|}
\hline \multicolumn{4}{|c|}{ Case study } \\
\hline Organisation & $\begin{array}{l}\text { Job title of } \\
\text { Participants }\end{array}$ & $\begin{array}{l}\text { Workshop } 1 \\
\text { (Clash detection and } \\
\text { classification) }\end{array}$ & $\begin{array}{l}\text { Workshop } 2 \\
\text { (Quantification of } \\
\text { clashes) }\end{array}$ \\
\hline $\begin{array}{l}\text { PMC Project } \\
\text { Management } \\
\text { Consultant } \\
\text { (Client } \\
\text { representative) }\end{array}$ & $\begin{array}{l}\text { Senior Project } \\
\text { Manager } \\
\text { Project } \\
\text { Coordinator }\end{array}$ & $\checkmark$ & $\checkmark$ \\
\hline $\begin{array}{l}\text { Technical } \\
\text { Consultants }\end{array}$ & $\begin{array}{l}\text { BIM consultant of } \\
\text { the project } \\
\text { Senior BIM } \\
\text { Manager } \\
\text { Senior project } \\
\text { manager } \\
\text { Project manager }\end{array}$ & $\begin{array}{l}\checkmark \\
\checkmark \\
\checkmark \\
\checkmark \\
\checkmark\end{array}$ & $\begin{array}{l}\checkmark \\
\checkmark\end{array}$ \\
\hline Cost Surveyor & $\begin{array}{l}\text { Cost control } \\
\text { Manager } \\
\text { Chief Quantity } \\
\text { Surveyor }\end{array}$ & $\begin{array}{l}x \\
x\end{array}$ & $\begin{array}{l}\checkmark \\
\checkmark\end{array}$ \\
\hline & & Total [6] & Total [8] \\
\hline
\end{tabular}

Interviews took place to understand the process of clash detection and the applied practices in categorising detected clashes and in dealing with resolution procedures. The output of those interviews enabled a better understanding of the applied clash detection and resolution processes and highlighted gains and restrictions. The development and review of the quantification schema was done iteratively with five interviewees.

The interviewees had at least five years of industrial experience in BIM related roles. Questions asked were related to information requirements for clash detection; participants involved; quantification methodology; and definition of the two scenarios i.e. BIM based clash detection, and assessment of cost implications of clashes.

The schema was validated by implementing on a multi-million-dollar case study comprising the interface of two projects. Two workshops were conducted in the case study and the participants involved are described in Table 4. The quantification schema was applied to two 
interfacing projects involving project consultants that participated as the industry experts for the validation of the developed schema as per the process flow shown in Figure 1.

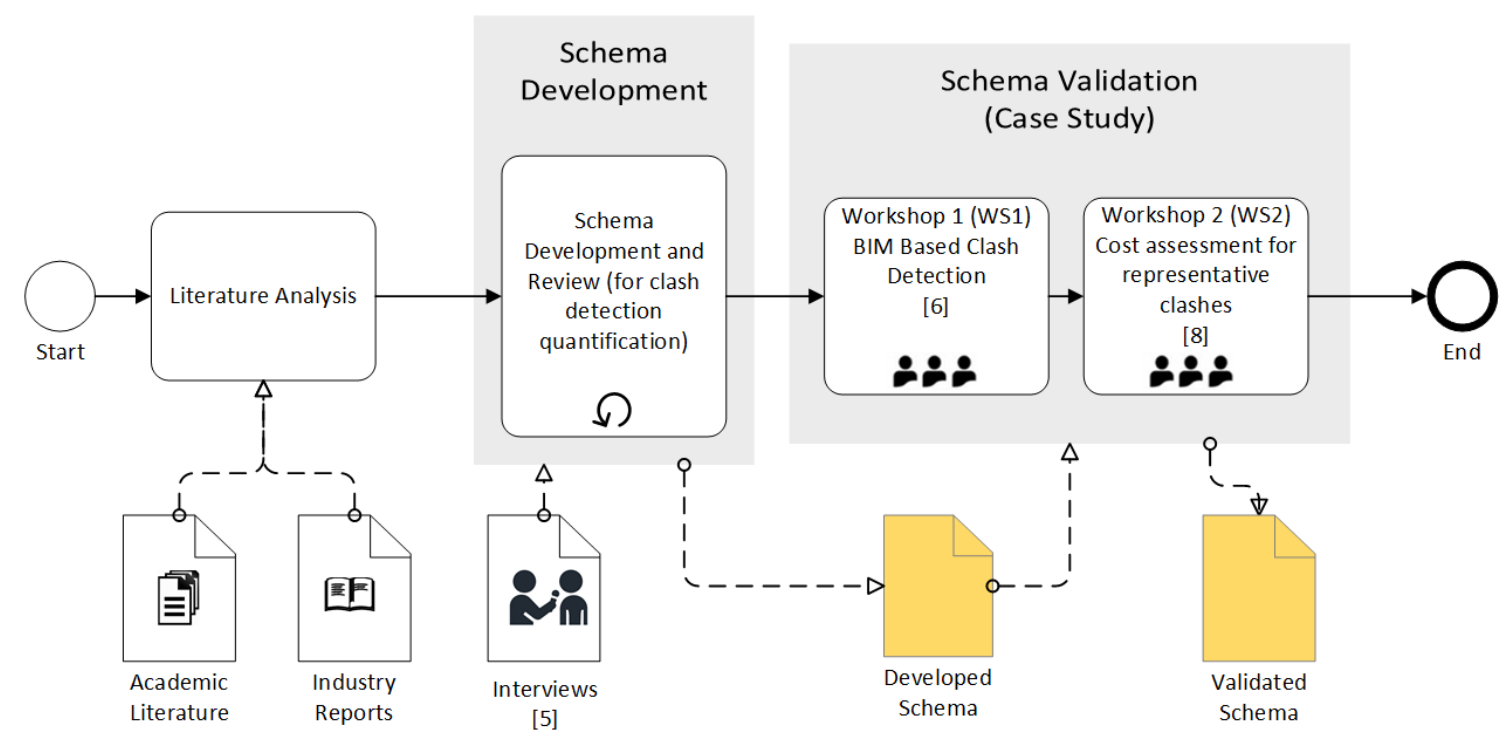

Figure 1: Schema Development process flow

The 'case study' included two workshops. Workshop 1 and 2 (WS1 and WS2). WS1 was conducted towards evaluation of BIM based clash detection and WS2 was used for assessment of cost implications of clashes; both are required to complete the quantification schema validation.

The applied research methodology for schema development relies on the collaboration efficiency and expertise of interviewees and workshops' participants towards categorising the clashes. This multi-disciplinary collaboration is conducted to reduce clashes within a BIM enabled project. The schema is validated by one case study as it was considered sufficient to show the applicability of the developed schema, and due to the volume and representativeness of the projects. Model coordination was fully applied to the two projects, but the schema for quantification was only applied where the two projects physically interfaced. All identified clashes were categorised based on the developed schema. A detailed example was provided for each category (major-medium-minor) to the interviewees. Table 5 provides a summary of the data source collection for the study. 
Table 5: Data sources for the study

\begin{tabular}{|c|c|c|}
\hline Items & $\begin{array}{l}\text { Data } \\
\text { Source }\end{array}$ & Description \\
\hline 1 & Literature & $\begin{array}{l}\text { Penn State Design Coordination process maps were used to } \\
\text { develop an adaptable schema Saluja (2009); Messner et al. } \\
\text { (2019). Other sources used include; Staub-French and } \\
\text { Khanzode, (2007); Riley and Horman, (2001); Gijezen, et } \\
\text { al., (2010); Tommelein and Gholami, (2012; Parn et al., } \\
\text { (2018); PwC, (2018a, 2018b); Neelamkavil and Ahamed } \\
\text { (2012); and Azhar et al. (2012). }\end{array}$ \\
\hline 2 & Interviews & $\begin{array}{l}\text { Five participants took part in the interviews. All participants } \\
\text { had a minimum of } 5 \text { years BIM related experience } \\
\text { worldwide. Interviews were used to develop the schema for } \\
\text { quantifying clash detection. Interviews took on average of } \\
\text { 45-60 minutes. Questions used for the interviews were } \\
\text { centred on strategies for collecting and quantifying BIM } \\
\text { clashes within a BIM enabled project }\end{array}$ \\
\hline 3 & Case study & $\begin{array}{l}\text { The case study was conducted to validate the developed } \\
\text { schema. Two workshops took place. WS1 and WS2. } \\
\text { WS1 was organised to conduct BIM based clash } \\
\text { identification and implementation of clash categories. The } \\
\text { duration of the WS1 was one Week. Clashes were } \\
\text { documented in 3D for three different clash categories. }\end{array}$ \\
\hline & & $\begin{array}{l}\text { WS2 was done to explore the consequences of not adopting } \\
\text { BIM enabled Clash detection processes with a project. The }\end{array}$ \\
\hline
\end{tabular}




\begin{tabular}{|l|l|}
\hline & $\begin{array}{l}\text { participants of WS1 also participated in WS2. The } \\
\text { workshop was conducted within two weeks. Clashes were } \\
\text { quantified for their cost impact if they were not detected } \\
\text { virtually. }\end{array}$ \\
\hline
\end{tabular}

\section{Schema for categorisation and quantification of clash detection savings}

The main purpose of this study includes developing a schema for quantification of Clash detection savings and the validation of this schema. Literature review and experts' interviews showed the need to develop a schema that is easy to apply by project teams in practice and highlight BIM savings and thus encourage its wide adoption. As stated by Sacks (2016), a distinct approach to process flow improvement allows bringing benefits to the overall production process. This is done by "removing, as far as possible, non-value adding steps such as moving, waiting and inspection, and by minimising set-up times and rework". The schema takes ground on industry current clash detection good practice process maps, and further applies a systematic clash classification and valuation developed by a combination literature analysis and interviews. The schema for quantification of the clash detection savings is depicted in Figure 2, and further explained in the section remainder. 


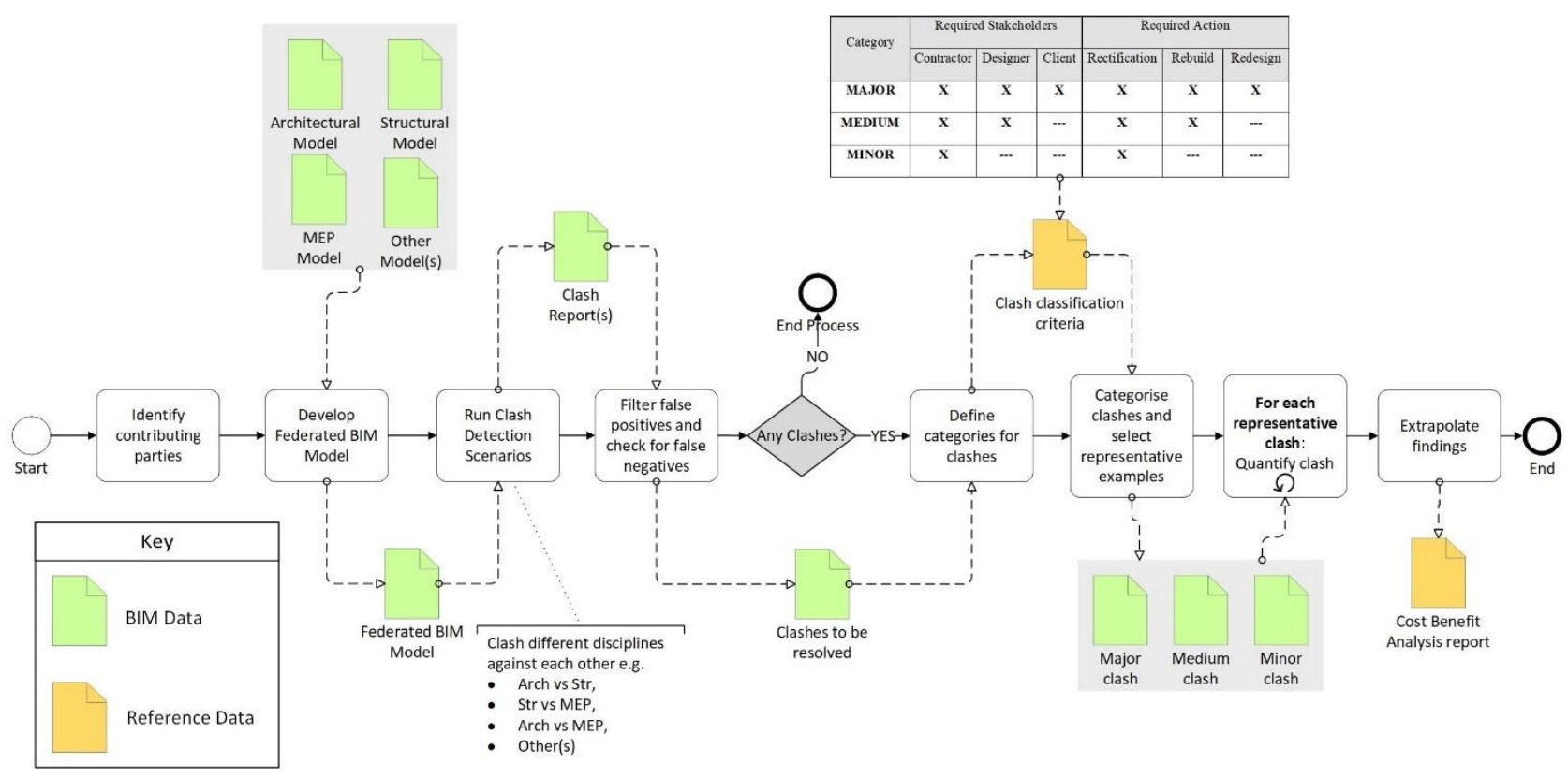

Figure 2: Schema for quantification of BIM enabled clash detection savings

\section{Identify contributing parties:}

The schema requires the identification of the contributing parties for the quantification process, which would vary from project to project depending on project phase and size. It is vital that key stakeholders are involved in clash detection and resolution, i.e. BIM managers, BIM coordinators; design managers, discipline leads, construction managers, etc participate in the quantification process. For further steps, the participation of planning team members, quantity surveyors is also useful to assist in the quantification process as shown later in the case study.

\section{Develop federated BIM model}

The BIM enabled clash detection process requires a federated BIM model that is achieved by combining individual discipline models and other reference models into a single model, which is usually done in a model review tool such as Autodesk-Navisworks® or Solibri-ModelChecker®. 


\section{Run clash detection scenarios}

Following the development of the federated BIM model, the clash detection scenarios are run where different disciplines models are clashed against each other e.g. Architecture vs Structure, Architecture vs MEP, MEP vs Structure and the review tool is configured to output results in the form of reports or colour coded / highlighted elements in the federated BIM models. The resulting identified clashes are then categorised in the next steps.

\section{Filter false positives and check for false negatives}

The clash detection algorithm used in design coordination tools can lead to a number of clashes not all of which may be relevant (Leite et al., 2011) and therefore need to be filtered. Similarly, the BIM model need to be inspected for any clashes which are not detected by the design coordination software however there is a possibility that these can be missed due to human error.

\section{Define categories for detected conflicts}

The categorisation should be based on the clash magnitude in terms of change impact and dependency on stakeholder involvement. Two major criteria are identified to be cost drivers when resolving detected conflicts. These are:

- Required Stakeholders to be involved, i.e. contractor, designer and/or client

- Required actions to be taken, i.e. rectification, rebuilt and/or redesign

Table 6 shows categorisation of clashes identified. Depending on who to involve and how to act while resolving conflicts, three categories are defined, i.e. Major, Medium and Minor. 
Table 6: Clashes Categorisation

\begin{tabular}{|c|c|c|c|c|c|c|}
\hline \multirow{2}{*}{ Category } & \multicolumn{3}{|c|}{ Required Stakeholders } & \multicolumn{3}{c|}{ Required Action } \\
\cline { 2 - 7 } & Contractor & Designer & Client & Rectification & Rebuild & Redesign \\
\hline MAJOR & X & X & X & X & X & X \\
\hline MEDIUM & X & X & --- & X & X & --- \\
\hline MINOR & X & --- & --- & X & --- & --- \\
\hline
\end{tabular}

For example, a major conflict or clash will require the involvement of designer and client team in addition to contractor, because a design change may be needed and would require client's approval. A medium clash will require the input of the contractor and the approval of the designer of proposed resolution, while the contractor can independently resolve a minor clash without going back to designer or to client. While a minor clash can easily be rectified by the contractor.

The categories were identified based on interviews and existing Clash detection process maps similar to those developed by Penn State (Saluja, 2009; Messner et al., 2019). However, the involvement of stakeholders towards clash resolution was explored with industry experts. Gijezen et al., (2010) stated the use of work breakdown structure to define clashes leading to change orders demanding the attention of the designers or other relevant stakeholders within the project delivery process. In addition, the impact of clashes affecting activities on critical path or activities involving Bill of Quantities (BOQ) positions of high costs can be taken into account for categorisation during clash resolution process. Specific interview questions were incorporated while defining those categories, especially those related to strategies for clash categories, stakeholders required for the resolution of different clash categories, identifying gap between BIM based clash detection and traditional clash detection when dealing with clashes. The clash 
detection factors (hard/soft) identified in the literature review section can also be integrated for quantification purposes.

\section{Categorise clashes and select examples}

Example of each category can be selected to show the different nature of the different clash categories within a BIM enabled project. However, it is required to conduct a sequential quantification for each clash as the cost for resolution of similar clashes could vary depending on the context. For example, resolution requiring design changes might require the participation of the client. However, cost towards design changes would vary depending on the scenario. This specifies the need for cost ranges within a categorised clash. The ranges can be adopted to other similar projects.

\section{Quantify scenarios}

The selected sample in each category can be systematically quantified to estimate cost of BIM based clash detection and estimation of cost implication of those clashes. In order to quantify the cost impact of clashes, considerations are made for construction work that would take place if clashes were not virtually detected using BIM prior to construction. This quantification serves as a guide to suggest a range and an average for clashes of such category. Contractor and designers under the leadership of the PMC quantify the cost impact of the highest and lowest clash in each category. The number of clashes in the same category then multiplies the average. There is a limitation to this quantification process as the individual cost of clashes in each category could vary. For a more robust analysis, each clash can be quantified and the sum of each clash in each category can be tabulated. However, this would make the process complex and long.

\section{Extrapolate findings}

Information about the nature of the clashes can help stakeholders to make informed decisions. There would be different clash categories at different project stages as shown in Table 6 . The 
information on clashes found at the different stages can inform project teams to focus on robust analyses of clashes at defined stages. These could vary from project to project.

\section{Case study}

The study comprises the coordination among disciplines at the interface between two projects (A and B): A rail tunnel infrastructure project and a boulevard street with below ground car park facilities, roads and utilities. The design of individual projects was complete and construction underway but for the interface of the two projects, construction had not started. This interface is the scope of the case study. The proposed quantification schema was presented to the two project representatives for review one week before conducting the workshops. The process adopted a simplified process that was clearly explained. They were asked to comment on the data collection, analysis and quantification methods. The two teams did not report any changes. In preparations for the workshops, It was initiated to highlight the monetary advantage achieved through Clash detection and was mainly done by owner's consultants that handled BIM scope; followed up on coordination meetings, sorted all detected inter-package clashes, recorded approved resolutions, estimated quantities, set up categorisation measurements and presented findings to other project parties. The contractors of each project were provided with 2Dcoordinated design and had to confirm coordination with BIM during construction. BIM was first introduced during construction since design was traditionally developed in 2D. Contractors' BIM teams were yet to detect and resolve design conflicts using 3D models that had to be developed based on 2D design drawings. The coordination of potential conflicts at interface area was very important for the owner but not included in contractors' scope. They were detected later by owner's BIM Consultant organisation which collaboratively managed and resolved through multiple coordination meetings with stakeholders. Among these coordination meetings the developed schema was implemented through two workshops which were conducted for BIM based clash detection and assessment of cost impact of clashes. 


\section{Workshop 1 (WS1): BIM based clash detection and categorisation}

The schema was developed and ready for validation. The BIM based clash detection is the actual work conducted within the project to save cost. The workshop had six participants (see Table 4). Thousands of clashes were detected within each project, $[\mathrm{A}]$ and $[\mathrm{B}]{ }^{1}$ separately. However, this study only focuses on the interface project-to-project clashes and their prospective savings. Since design coordination at the interface between the two projects fell under client's responsibility, the client BIM management consultant team processed a thorough clash detection between the two projects (A and B) after the respective contractor provided their models. This resulted in a comprehensive list giving an overview on each report to allow further analysis. The developed schema was applied on this interface of two projects as a case study with the following outcome resulting from each step.

\section{Identifying contributing parties/ stakeholders.}

The BIM consultant conducted the study with support from relevant stakeholders. In addition, the client's BIM team also made efforts to detect clashes and initiate coordination meetings to assign responsibilities and suggest resolutions.

\section{Defining categories}

Together with the PMC, the list of detected clashes was analysed and sorted based on a categorised measure and clash complexity factors. The categorisation suggested in the schema was deemed proper for the project, so that clashes could be assigned to major, medium or minor categories as per their specific change impact and stakeholder involvement. Clash factors (hard/soft) had no impact since the focus was set on resolving hard clashes in a first step.

\footnotetext{
${ }^{1}$ Actual project name is anonymized
} 


\section{Categorising clashes and setting examples}

Clashes are categorised into major, medium and minor groups. After the analysis, 74 clashes were assigned to the defined categories, considering the criteria of required stakeholders and actions. See Table 7, it gives an overview of the results.

Table 7: Listing and categorisation summary of all clash instances

\begin{tabular}{|c|c|c|c|}
\hline Involved Disciplines & Major & Medium & Minor \\
\hline IRRIGATION VS. STRUCTURE & 0 & 1 & 12 \\
\hline SEWAGE VS. STRUCTURE & 1 & 5 & 6 \\
\hline ELECTRICAL VS. STRUCTURE & 0 & 1 & 3 \\
\hline PORTABLEWATER VS. & & & \\
\hline STRUCTURE & 0 & 1 & 3 \\
\hline PNEUMATIC WASTE VS. & & & \\
\hline STRUCTURE & 0 & 3 & 0 \\
\hline DISTRICT COOLING VS. & & & \\
\hline STRUCTURE & 1 & 0 & 1 \\
\hline TELECOMMUNICATION VS. & & & \\
\hline STRUCTURE & 0 & 1 & 1 \\
\hline VARIOUS 66KV HARD & & & \\
\hline CLASHES & 0 & 0 & 12 \\
\hline VARIOUS 66KV SOFT CLASHES & 0 & 4 & 7 \\
\hline OTHERS & 1 & 9 & 1 \\
\hline Total & 3 & 25 & 46 \\
\hline
\end{tabular}

The team chose one example to represent each category of the three examples incorporating the BIM scenario in which 3D views from the consolidated model of both projects' 
disciplines are represented. In addition, the conflict and its agreed resolution was described in the first workshop. This is followed by quantification of the cost implication of clash undetected during construction in a second workshop that answered the question: what if this conflict was not detected on time and what cost impact it will have had? Only after analysing both scenarios, the quantification of each example could be conducted. BIM supported this effort by providing required information related to quantities, BOQ codes, rates and time/duration for the time clashes.

\section{Workshop 2 (WS2): Assessment of cost implication of clashes}

Workshop 2 (WS2) was used to assess the consequences of not adopting the BIM enabled Clash detection. These were conducted with project managers from both project A and B. The assessment of cost implication of clashes was proposed for the same clashes identified in WS1 in Major, Medium, and Minor categories. Eight participants were involved in WS2 (see Table 4). The Project Management Consultant (PMC) team assessed implication of those clashes, had they not been identified, based on the specifics of the project, contract's nature and site situation. The Cost Management Consultant (CMC) facilitated in establishing the cost for BIM based clash detection as well as costing the impact of clashes if they remained undetected and unresolved. The CMC populated the works in each scenario determined by the PMC and assigned the corresponding BOQ codes and unit rates. All the clashes were prevented due to BIM enabled Clash detection. However, it is vital that these scenarios are tabulated systematically to quantify the possible savings through BIM. The CMC and PMC are vital in identifying what was prevented and to estimate potential cost savings during construction by avoiding the clash.

\section{Major Category Example}

Presenting BIM based Clash detection: 
Conflict Description: Package [A] 1.2m storm water line; clashes with package [B] top of hood structural slab

BIM Resolution: The hood was relocated $18.5 \mathrm{~m}$ to the south in preconstruction model. The already erected hood rebar was to be dismantled.

Figures 3 and 4 present how the design issues were identified (Base Line) and addressed (BIM Resolution). Table 8 shows the cost of BIM enabled clash detection.

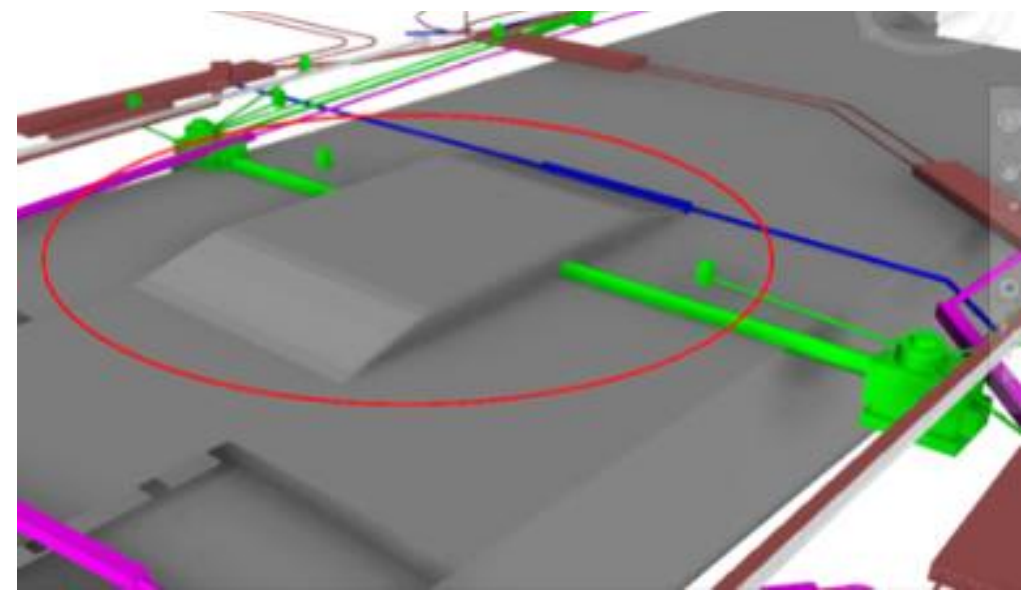

Figure 3: Baseline 3D visualization of Major Category Clash Example

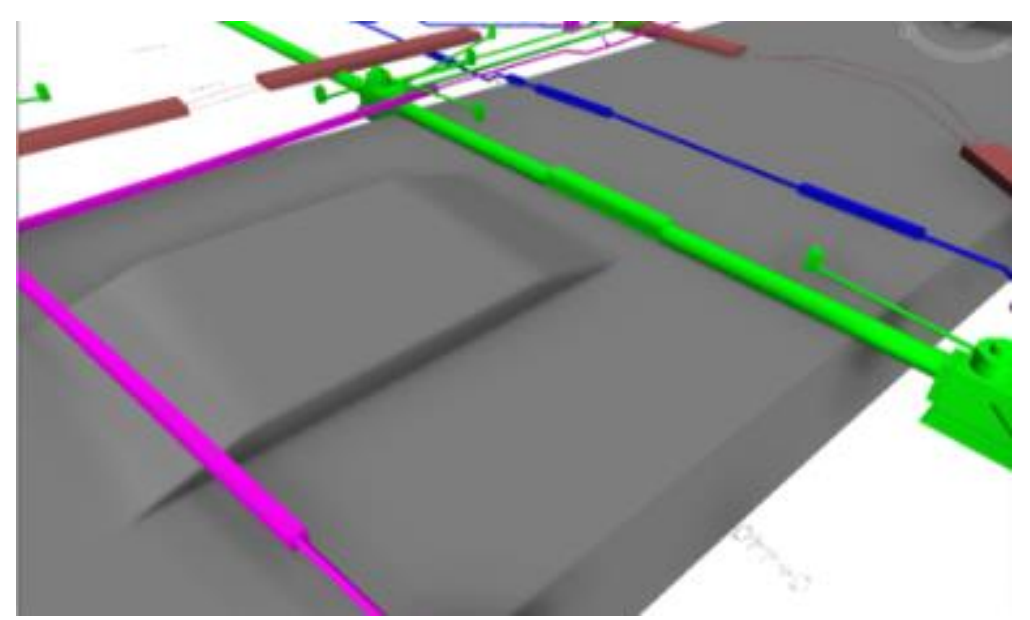

Figure 4: BIM-enabled Clash Resolution 3D visualization of Major Category Clash Example 
Table 8: Cost of BIM enabled Clash detection and resolution for major clash category

\begin{tabular}{|l|l|l|l|l|}
\hline & Item & Description & Quantity & Unit \\
\hline BIM* & 1 & Coordination and BIM management & 1 & Sum \\
\hline Redundant & 2 & Dismantle of Rebar & 90 & Hour \\
Work & & & & \\
\hline Total Estimated Costs - BIM based clash detection: $\mathbf{\$ 9 , 8 2 2}$ & & \\
\hline
\end{tabular}

*Not including contractors' costs

Establishing Cost Implications of Major Clash:

If this clash was not detected, the construction of the hood would have been executed first, then when the layout of the storm water network would have started as planned, it would have been stopped to address the clash with the following resolution as the only scenario deemed applicable:

- Redesign the location of the hood.

- Demolish the already built hood.

- Demolish the new roof area

- Rebuild the relocated hood.

The redesign of the $1.2 \mathrm{~m}$ Storm Water route to side pass the hood structure and elevate the length of the line all the way to the west (app 1.8km) was excluded and concluded to be improbable. The quantification of scenarios included the number of item in context with description that would facilitate the estimation procedure. Materials are quantified in units. These are in square meters, cubic meters, numbers, ton, or days. Furthermore, the contractors sum is 
excluded from the quantification. The items considered for the quantification are described in Table 9.

Table 9: Estimation of cost implication of a major clash

\begin{tabular}{|c|c|c|c|c|}
\hline & Item & Description & Quanti & Unit \\
\hline & 1 & Excavation to clear area beyond original design & 4,222 & $\mathrm{~m}^{3}$ \\
\hline & 2 & Demolition of $1.8 \mathrm{~m}$ thick Hollow Slab & 905 & $\mathrm{~m}^{2}$ \\
\hline & 3 & $\begin{array}{l}\text { Formwork Fair finish; Plane horizontal, width } \\
\text { exceeding } 1.22 \mathrm{~m}\end{array}$ & 650 & $\mathrm{~m}^{2}$ \\
\hline & 4 & Hollow Core for Tunnel's Roof Hollow Slab & 20 & No \\
\hline & 5 & $\begin{array}{l}\text { Deformed high yield steel bars to BS } 4449 \text { To } \\
\text { suspended slabs }\end{array}$ & 2.20 & Ton \\
\hline & 6 & (Provision) Design mix, concrete grade C50 & 754 & $\mathrm{~m}^{3}$ \\
\hline & 7 & $\begin{array}{l}\text { (Placing) To Suspended Slabs; Thickness } \\
\text { exceeding } 500 \mathrm{~mm}\end{array}$ & 754 & $\mathrm{~m}^{3}$ \\
\hline & 8 & $\begin{array}{l}\text { Fair finish; width exceeding } 1.22 \mathrm{~m} \text { To soffits of } \\
\text { Slabs }\end{array}$ & 650 & $\mathrm{~m}^{2}$ \\
\hline & 9 & Construction Joints to Slabs & 64.38 & $\mathrm{~m}^{2}$ \\
\hline & 10 & Water stop at Construction Joints (CJ) in Slabs & 36 & $\mathrm{M}$ \\
\hline & 11 & Filling & 4,222 & $\mathrm{~m}^{3}$ \\
\hline & 12 & Waterproofing membrane and PVC liner & 620 & $\mathrm{~m}^{2}$ \\
\hline Others & 13 & $\begin{array}{l}\text { [B] Contractor: Delay (Prolongation) } \\
\text { Preliminaries (Performance Bond/Insurance, } \\
\text { temp. works etc. for the above additional scope) }\end{array}$ & 19 & Day \\
\hline
\end{tabular}




\begin{tabular}{|l|l|l|l|}
\hline 14 & $\begin{array}{l}\text { [A] Contractor: Delay (Prolongation) } \\
\text { Preliminaries (Performance Bond/Insurance, } \\
\text { temp. works etc. for the above additional scope) }\end{array}$ & 19 & Day \\
\hline
\end{tabular}

\section{Medium Category Example}

Presenting BIM based Clash detection:

Conflict Description: Package [A] 66kV line; clashes with package [B] retaining Wall Structure BIM Resolution: The $66 \mathrm{kV}$ line has been dropped locally. Figures 5 and 6 present how the design issues were identified (Base Line) and addressed (BIM Resolution). Table 10 provide cost towards BIM Clash detection.

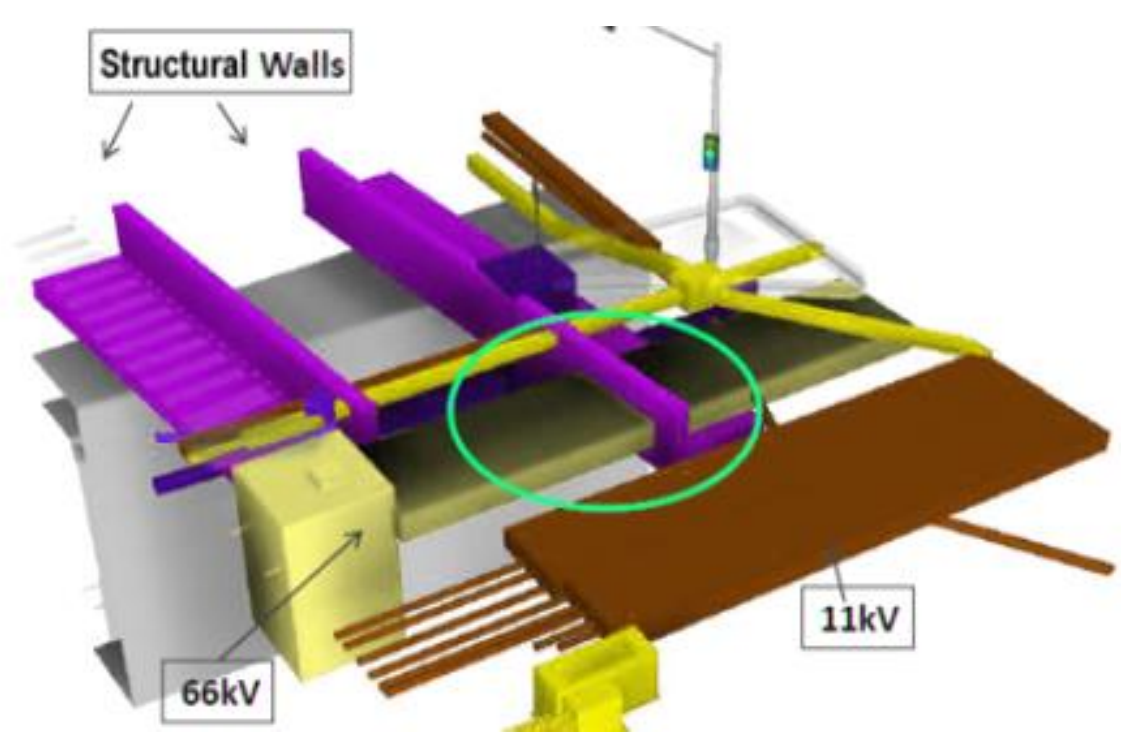

Figure 5: Baseline 3D visualization of Medium Category Clash Example 


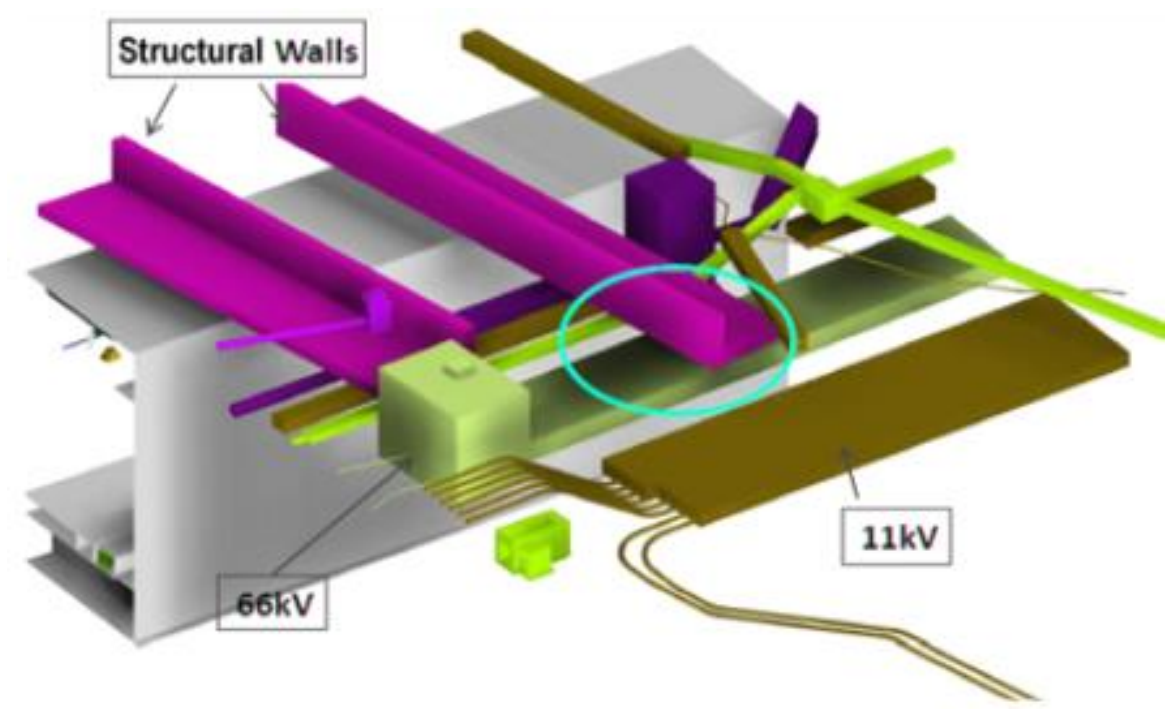

Figure 6: BIM-enabled Clash Resolution 3D visualization of Medium Category Clash Example

Table 10: Cost of BIM enabled Clash detection and resolution for medium clash category

\begin{tabular}{|l|l|l|l|l|}
\hline & Item & Description & Quantity & Unit \\
\hline BIM* $^{*}$ & 1 & Coordination and BIM management & 1 & Sum \\
\hline
\end{tabular}

Total Estimated Costs - BIM based clash detection: $\mathbf{\$ 5 , 8 0 0}$

*Not including contractors' costs

Establishing Cost Implications of Medium Clash:

The breakdown of cost due to a medium clash is presented in Table 11. If this clash was not detected, the construction of the $66 \mathrm{kV}$ would have executed first, and then when the layout of the structural walls \& multi tubular ducts was to start, it would have stopped to address the clash with the following resolutions scenarios:

Scenario 1:

- Redesign / Approvals (Authorities \& other stakeholders Coordination)

- Redesign wall details to over pass $66 \mathrm{kV}$ duct 
Scenario 2: (This elevates this case to Major)

- Redesign $66 \mathrm{kV}$ to lower level

- Program delay to both projects

- Delay to overall energization

Table 11: Estimation of cost implication of a medium clash

\begin{tabular}{|c|c|c|c|c|}
\hline & Item & Description & Quantity & Unit \\
\hline \multirow{11}{*}{ Contractor } & 1 & Excavation to clear area beyond original design & 1,200 & $\mathrm{~m}^{3}$ \\
\hline & 2 & Waterproofing membrane and PVC liner & 420 & $\mathrm{~m}^{2}$ \\
\hline & 3 & $\begin{array}{l}\text { Formwork Fair finish; Plane horizontal, width } \\
\text { exceeding } 1.22 \mathrm{~m}\end{array}$ & 120 & $\mathrm{~m}^{2}$ \\
\hline & 4 & 300mm Concrete wall/slab boring & 8 & No \\
\hline & 5 & Pipe Works - Depth; $3.5-4.0 \mathrm{~m}$ & 45 & $\mathrm{~m}$ \\
\hline & 6 & (Provision) Design mix, concrete grade C50 & 220 & $\mathrm{~m}^{3}$ \\
\hline & 7 & $\begin{array}{l}\text { (Placing) To Suspended Slabs; Thickness exceeding } \\
500 \mathrm{~mm}\end{array}$ & 220 & $\mathrm{~m}^{3}$ \\
\hline & 8 & $\begin{array}{l}\text { Fair finish; width exceeding } 1.22 \mathrm{~m} \text { To soffits of } \\
\text { Slabs }\end{array}$ & 120 & $\mathrm{~m}^{2}$ \\
\hline & 9 & Construction Joints to Slabs & 32 & $\mathrm{~m}^{2}$ \\
\hline & 10 & Water stop at Construction Joints (CJ) in Slabs & 16 & $\mathrm{~m}$ \\
\hline & 11 & Back Filling beyond original design & 2,111 & $\mathrm{~m}^{3}$ \\
\hline
\end{tabular}




\begin{tabular}{|l|l|l|l|l|}
\hline \multirow{2}{*}{ Others } & 12 & $\begin{array}{l}\text { [A] Contractor: Delay (Prolongation) Preliminaries } \\
\text { (Performance Bond/Insurance, temp. works etc. for } \\
\text { the above additional scope) }\end{array}$ & 14 & Day \\
\cline { 2 - 5 } & 13 & Other (reinstatement of demolished slabs) & 1 & Sum \\
\hline
\end{tabular}

\section{Minor Category Example}

Presenting BIM based Clash detection:

Clash Description: Package [A] wall structure clashes with package [B] LV pipes and utilities BIM Resolution: Project [B] LV pipelines have been rerouted to avoid collision with structures. Project [A] structural walls designed with pre-engineered sleeves to run utilities through as shown in Figure 7.

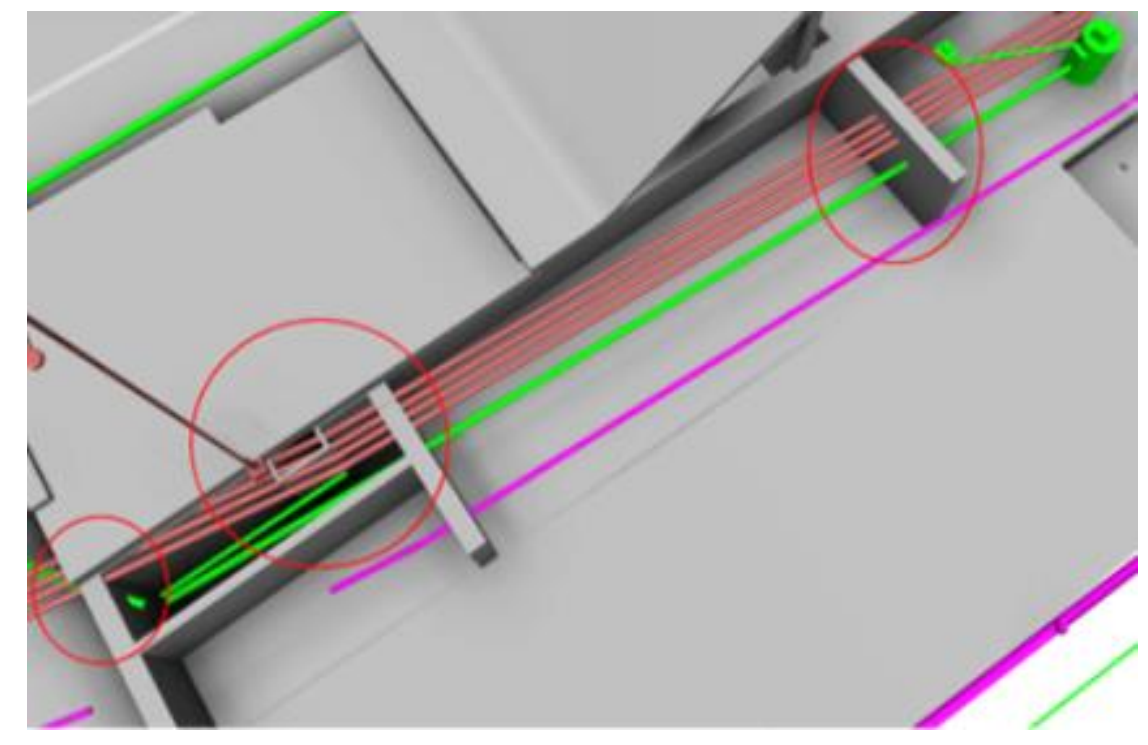

Figure 7: Baseline 3D visualization of Minor Category Clash Example

Table 12: Cost of BIM enabled Clash detection and resolution for minor clash category 


\begin{tabular}{|l|l|l|l|l|}
\hline & Item & Description & Quantity & Unit \\
\hline BIM* & 1 & Coordination and BIM management & 1 & Sum \\
\hline
\end{tabular}

Total Estimated Costs - BIM based clash detection: $\$ 1,450$

*Not including contractors' costs

Table 12 provide tabulation of Clash detection cost towards minor clash. Three different clashes from different categories have being presented above. However, the consequence of adopting BIM for the same clashes needs to identify for the purpose of quantify cost savings.

Establishing Cost Implications of Minor Clash:

If this clash was not detected, the BIM resolution would have executed on site instead of a preconstruction model in addition to extra excavations. Forty-six similar cases have been identified as "Minor" cases; most of which included avoiding thick concrete boring and quantity elimination. These would have led to three on-site tasks. These are extra excavation, rerouting LV pipes and boring (12 total). The BIM scenarios enable the opportunity to prevent rework thus contributing towards saving resources. Table 13 provides the cost of the minor clashes when unresolved.

Table 13: Estimation of cost implication of a minor clash

\begin{tabular}{|l|l|l|l|l|}
\hline Minor & Item & Description & Quantity & Unit \\
\hline \multirow{4}{*}{ Contractor } & 1 & $* 300 \mathrm{~mm}$ Concrete wall/slab boring & 12 & No \\
\cline { 2 - 6 } & 2 & Pipe Works - Depth; 3.5 - 4.0 m & 5 & $\mathrm{M}$ \\
\cline { 2 - 6 } & 3 & Waterproofing membrane and PVC liner & 5 & $\mathrm{~m}^{2}$ \\
\cline { 2 - 6 } & 4 & Screed protection; 75 mm thick & 6 & $\mathrm{~m}^{2}$ \\
\hline
\end{tabular}




\begin{tabular}{|l|l|l|l|}
\hline Other & 5 & $\begin{array}{l}\text { Delay (Prolongation) Preliminaries (Performance } \\
\text { Bond/Insurance, temp. works etc. for the above } \\
\text { additional scope) }\end{array}$ & Day \\
\hline
\end{tabular}

\section{Extrapolated findings}

To summarise the study, WS1 and WS2 findings were tabulated together. The examples on major, medium and minor categories' estimates for both workshops above were taken as a guidance to come up with a range of cost saved in each clash category as shown in the Figure 8 below. Looking at the details of the presented examples, significant costs would have incurred due to time delays on site in the non-BIM scenario where BIM based clash detection and resolution did not take place. However, the cost implications of delays were not considered for the purpose of this study. Further savings could have been included in the estimate if delays were factored into the quantification process.
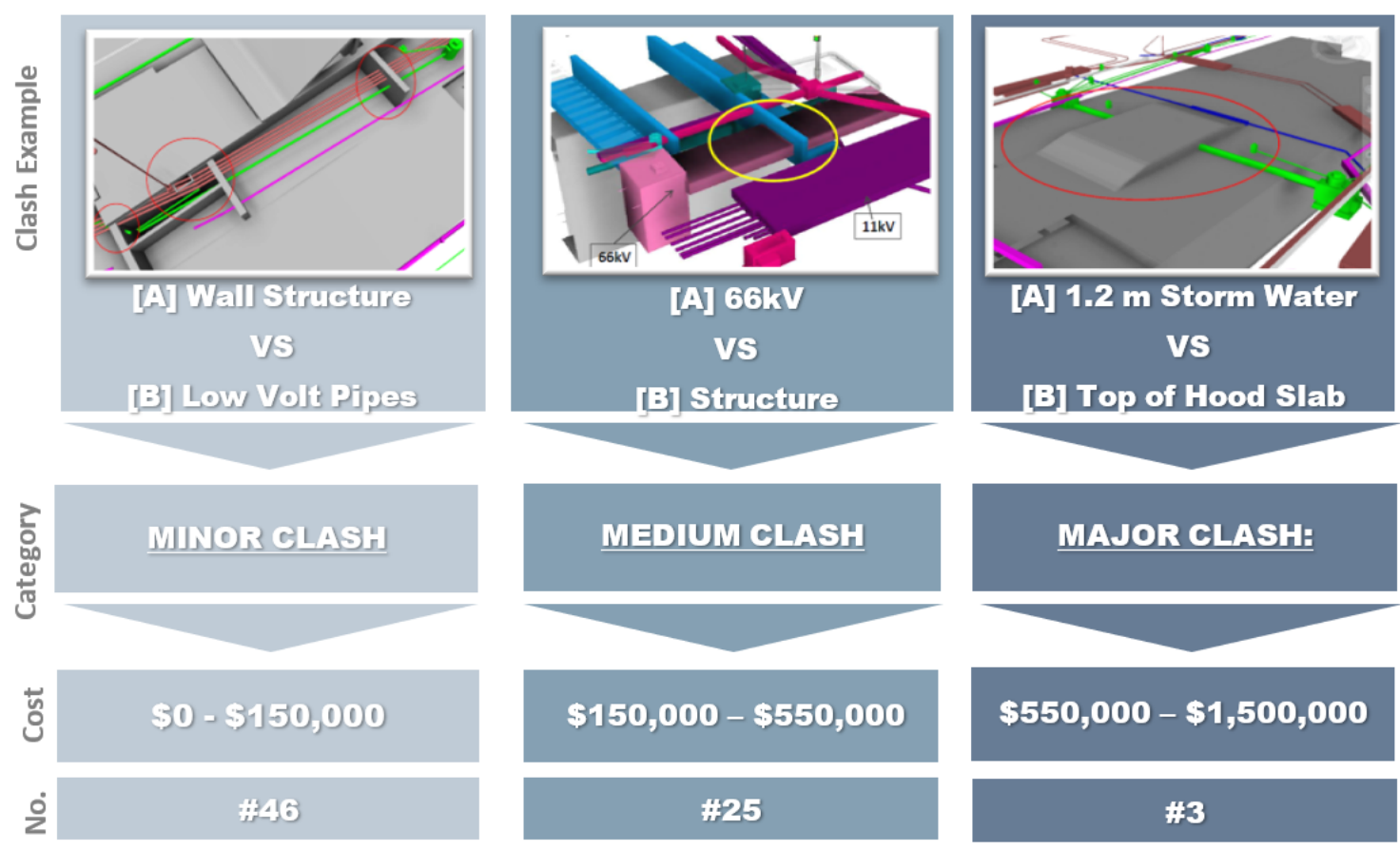
Figure 8: Overview on conflicts' categories, examples, cost ranges and numbers A cost has been identified for each category of clash. An average was considered for all categories to allow for variation in projects. The quantification was achieved by multiplying the average of each category by the number of conflicts clustered in respective category. The outcomes will extrapolate to the overall cost savings achieved by this particular case study. As a result, a total saving of around $\$ 15,275,000$ is estimated (Table 14) on exclusive project to project interface clashes representing about $20 \%$ of contract value (USD 75 Million) of the scope under consideration.

Table 14: Extrapolated overall achieved savings

\begin{tabular}{|c|c|c|c|c|c|c|c|c|c|c|c|}
\hline \multirow[t]{2}{*}{ Category } & \multicolumn{3}{|c|}{$\begin{array}{c}\text { Required } \\
\text { Stakeholders }\end{array}$} & \multicolumn{3}{|c|}{ Required Action } & \multicolumn{2}{|c|}{$\begin{array}{c}\text { Value } \$ \\
\text { (Thousands) }\end{array}$} & \multirow{2}{*}{\begin{tabular}{|c|} 
Avg \$ \\
(Thousands) \\
$\$$
\end{tabular}} & \multirow{2}{*}{\begin{tabular}{|l} 
Qty \\
No.
\end{tabular}} & \multirow{2}{*}{$\begin{array}{c}\text { Cost \$ } \\
\text { (Million) } \\
\$\end{array}$} \\
\hline & Contr & Dsgnr & r Clien & Rectification & Rebuild & Redesign & Min & Max & & & \\
\hline MAJOR & $\mathbf{X}$ & $\mathbf{X}$ & $\mathbf{X}$ & $\mathbf{X}$ & $\mathbf{X}$ & $\mathbf{X}$ & 550 & 1,500 & 1,025 & 3 & 3.075 \\
\hline MEDIUM & $\mathbf{X}$ & $\mathbf{X}$ & & $\mathbf{X}$ & $\mathbf{X}$ & & 150 & 550 & 350 & 25 & 8.75 \\
\hline MINOR & $\mathbf{X}$ & & & $\mathbf{X}$ & & & 0 & 150 & 75 & 46 & 3.45 \\
\hline & & & & & & & & & Total: & & $\$ 15.275$ \\
\hline
\end{tabular}

\section{Discussion}

A systematic adoption of a process flow to evaluate the impact of clash detection BIM-enabled process remains unknown in the current literature whilst the pertinence of a quantitative appraisal of cost-control benefits related to BIM is widely identified as a significant way forward to its implementation (Olawumi et al., 2018; Chan, Olawumi and Ho, 2019). The schema presented in the study was successfully developed using a blend of literature and interviews with experts and implemented in the case study of the interface of two projects where they physically interfaced: project A, a rail tunnel infrastructure; and project $\mathrm{B}$, a boulevard street with underground car park facilities, roads and utilities. 
Van der Vlist et al. (2014) discussed the relevance of information and communication technology adoption for firms to benefit in their production costs, but as stated by Sacks (2016), this is not a linear process, and consideration of distinct production and construction flows is needed to identify their overall influence on construction performance. This paper developed an approach to inform BIM processes benefit to the overall workflow. As a quantitative methodology, the use of the schema will help reduce the inadequate organisational workflows, easily ranked in the systematic clash detection process. The quantification schema is a simplified process to enable more stakeholders within the construction industry to adopt more effectively BIM-based clash detection, which is described as time consuming and stressful by PwC (2018a, 2018b). The classification criteria proposed as part of the schema facilitates the management and prioritisation of clashes. Depending on the degree of accuracy required, a range of representative clashes can be selected for quantifying the cost implications of the clashes if they were not resolved. The cost savings are calculated by using the cost of clash detection and cost saved if the clash went undetected for each representative clash. The estimates of cost savings of the representative clashes is then multiplied with the number of clashes to estimate overall savings achieved using BIM based clash detection which in the case study amounted to USD 15.2 Million ( 20\% of contract value of the scope under consideration), and therefore the value of adopting the process is justified.

The paper showed tangible savings, extending evidence of BIM positive impacts on AEC projects, as well as a methodology to conduct and replicate similar benefits and savings analysis for BIM-based clash detection on different projects. The contribution to literature is that the schema is industry focussed and industry-led, on a detailed substantial case study conducted to validate the schema. This currently represents a challenge, specifically because organisations account for varied expectations when it refers to BIM adoption, and a quantification on results helps objectivising the solution, as stated by Vass \& Karrbom Gustavsson (2017). 
While the paper gives a thorough insight into the quantification of savings due to BIM based clash detection and the schema can be applied on other projects, the number of people involved in interviews and workshops is limited and as a follow up, more experts can be involved to improve the cost estimation and classification process.

Demian and Walters (2014) defended a theoretical approach to measure information flow and exchange to show benefits from BIM utilisation, while this paper delivers a cost-focused comparative approach of a BIM-enabled project (centred on clash detection and coordination BIM processes) to the alternative of a project not supported by BIM-enabled clash detection during design. The question is whether this quantifiable approach can be transposed to other BIM uses, in order to achieve a holistic added value to BIM.

\section{Conclusion}

BIM technologies and processes have started to be utilised to underpin construction processes, but cost implications remain high and and organisational change need to be justified. The aim of the paper is to develop and implement clash detection quantification schema to demonstrate and estimate the value in terms of cost savings that can be achieved by using BIM enabled clash detection.

The schema was developed using a qualitative and inductive research methodology (i.e. using literature and expert interviews) and validated by implementing on a case study of a major infrastructure project to demonstrate the cost savings that can be achieved by BIM enabled clash detection. The schema included identification of clashes, categorisation of clashes, identification of representative clashes in each category, and estimation of cost of clashes if they were not resolved before construction.

This paper contributes to the evidence of the value added by using BIM. It demonstrates a simple approach towards identifying return on investments when BIM enabled Clash detection is adopted within a project. Furthermore, the case study has validated the developed schema and 
showed USD 15.2 Million ( 20\%) of savings in a USD 75 Million project (representing the interface of the two mega infrastructure project).

Further work can be developed as indicated in the body of the paper to extend the schema to include other factors such as (a) different project size and (b) design complexity to conduct more detailed value analysis and benefit realisation management. Furthermore, other BIM uses such as planning (4D), cost estimation and monitoring (5D), and others can be explored for conducting similar estimates of savings achieved by implementing them. The value proposition and analysis can include not just cost but other social and environmental values.

Until BIM is being implemented as a standard on major projects, researchers and BIM practitioners are encouraged to disseminate lessons learned and case studies indicating how BIM can improve traditional practice and lead to cost savings. This will spread the word, motivate further BIM investments and implementation initiatives in the industry that will certainly pay back in the form of cost and time saving, and better quality of work.

\section{References}

Akponeware, A. O. and Adamu, Z. A. (2017) 'Clash detection or clash avoidance? An investigation into coordination problems in 3D BIM', Buildings, 7(3), p. 75.

Althizer, J. (2016) 'The Financial Benefit of Using Technology for Clash Reduction', Hourigan, 22 July. Available at: https://www.hourigan.group/blog/financial-benefit-using-technologyclash-reduction/ (Accessed: 10 February 2020).

Ashcraft, H. W. (2008) 'Implementing BIM: A report from the field on issues and strategies', in Paper Presentation at the 47th Annual Meeting of Invited Attorneys.

Azhar, S., Khalfan, M. and Maqsood, T. (2012) 'Building information modelling (BIM): now and beyond', Construction Economics and Building, 12(4), pp. 15-28. doi: 10.5130/AJCEB.v12i4.3032.

Baldwin, A. N. et al. (1999) 'Modelling information flow during the conceptual and schematic stages of building design', Construction Management and Economics, 17(2), pp. 155-167. doi: $10.1080 / 014461999371655$.

Barlish, K. and Sullivan, K. (2012) 'How to measure the benefits of BIM - A case study approach', Automation in Construction, 24, pp. 149-159. doi: 10.1016/j.autcon.2012.02.008. 
Becerik-Gerber, B. and Rice, S. (2010) 'The perceived value of building information modeling in the US building industry', Journal of Information Technology in Construction (ITcon), 15(15), pp. 185-201.

Berdeja, E. P. (2014) 'Conflict analysis in a BIM based design', in.

Bernstein, H. M. and Jones, S. A. (2012) SmartMarket Report: The Business Value of BIM in North America. McGraw-Hill Construction.

Blaikie, N. (2009) Designing Social Research: The Logic of Anticipation. 2nd Edition. Polity.

Bockstael, D. and Issa, M. H. (2016) 'A methodology for contractor clash detection using building information modelling on commercial construction projects', Journal of Information Technology in Construction (ITcon), 21(16), pp. 233-249.

Bryman, A. (2016) Social Research Methods. Oxford University Press.

BSI (2007) 'BS 1192 : 2007 Collaborative Production of Architectural, Engineering and Construction Information - Code of practice'.

BSI (2013) 'PAS 1192-2:2013 Specification for information management for the capital / delivery phase of construction projects using building information modelling'. Available at: http://www.carillionplc.com/media/105185/building_information_modelling.pdf.

BSI (2014) 'PAS1192-3:2014 Specification for information management for the operation phase of assets using building information modelling'.

Chan, D. W. M., Olawumi, T. O. and Ho, A. M. L. (2019) 'Perceived benefits of and barriers to Building Information Modelling (BIM) implementation in construction: The case of Hong Kong', Journal of Building Engineering, 25, p. 100764. doi: 10.1016/j.jobe.2019.100764.

Demian, P. and Walters, D. (2014) 'The advantages of information management through building information modelling', Construction Management and Economics, 32(12), pp. 11531165. doi: 10.1080/01446193.2013.777754.

Eadie, R. et al. (2013) 'An analysis of the drivers for adopting building information modelling', Journal of Information Technology in Construction (ITcon), 18(17), pp. 338-352.

Giel, B. K. and Issa, R. R. A. (2013) 'Return on Investment Analysis of Using Building Information Modeling in Construction', Journal of Computing in Civil Engineering, 27(5), pp. 511-521. doi: 10.1061/(ASCE)CP.1943-5487.0000164.

Gijezen, S. et al. (2010) Organizing 3D building information models with the help of work breakdown structures to improve the clash detection process. University of Twente.

Guangbin, W., Wei, L. and Xuru, D. (2011) 'Exploring the high-efficiency clash detection between architecture and structure', in International Conference on Information Management and Engineering, Singapore.

Han, N., Yue, Z. F. and Lu, Y. F. (2012) 'Collision detection of building facility pipes and ducts based on BIM technology', in Advanced Materials Research. Trans Tech Publ, pp. 312-317. 
Handfield, R. B. (1994) 'Effects of concurrent engineering on make-to-order products', IEEE Transactions on Engineering Management, 41(4), pp. 384-393.

Hartmann, T. (2010) 'Detecting Design Conflicts Using Building Information Models: A Comparative Lab Experiment', in Proceedings of the 27th International Conference CIB W78. Cairo, Egypt.

Hoffer, E. R. (2016) Achieving strategic ROI measuring the value of BIM. Autodesk Inc. 2016. Available at: https://damassets.autodesk.net/content/dam/autodesk/www/solutions/pdf/Is-itTime-for-BIM-Achieving-Strategic-ROI-in-Your-Firm\%20_ebook_BIM_final_200.pdf.

$\mathrm{Hu}$, Y. and Castro-Lacouture, D. (2019) 'Clash Relevance Prediction Based on Machine Learning', Journal of Computing in Civil Engineering, 33(2), p. 04018060. doi: 10.1061/(ASCE)CP.1943-5487.0000810.

ISO (2018) 'ISO 19650-2: 2018', Organization and Digitization of Information about Buildings and Civil Engineering Works, Including Building Information Modeling (BIM)-Information Management using Building Information Modeling. Part, 2.

Jin, R. et al. (2017) 'BIM Investment, Returns, and Risks in China's AEC Industries', Journal of Construction Engineering and Management, 143(12), p. 04017089. doi: 10.1061/(ASCE)CO.1943-7862.0001408.

Korman, T. M., Fischer, M. A. and Tatum, C. B. (2003) 'Knowledge and reasoning for MEP coordination', Journal of Construction Engineering and Management, 129(6), pp. 627-634.

Kreider, R. and Messner, J. (2013) 'The Uses of BIM: Classifying and Selecting BIM Uses', State College-Pennsylvania, (September), pp. 0-22.

Latiffi, A. A. and Tai, N. H. (2019) 'The Influence of Building Information Modelling (BIM) towards Return on Investment (ROI) from the Perspective of Malaysian Developers: A Qualitative Approach', in MATEC Web of Conferences. EDP Sciences, p. 05007.

Leite, F. et al. (2011) 'Analysis of modeling effort and impact of different levels of detail in building information models', Automation in Construction, 20(5), pp. 601-609. doi: 10.1016/j.autcon.2010.11.027.

Mehrbod, S. et al. (2019) 'Beyond the clash: investigating BIM-based building design coordination issue representation and resolution', Journal of Information Technology in Construction (ITcon), 24(3), pp. 33-57.

Messner, J. et al. (2019) BIM Project Execution Planning Guide - Version 2.2. Computer integrated Construction Research Program, Penn State. Available at: https://psu.pb.unizin.org/bimprojectexecutionplanningv2x2/ (Accessed: 27 February 2020).

Neelamkavil, J. and Ahamed, S. S. (2012) The Return on Investment from BIM-driven Projects in Construction. National Research Council of Canada. doi: 10.4224/20374669.

Office for National Statistics (2019) Construction statistics, Great Britain: 2018. 
Olawumi, T. O. et al. (2018) 'Barriers to the integration of BIM and sustainability practices in construction projects: A Delphi survey of international experts', Journal of Building Engineering, 20, pp. 60-71. doi: 10.1016/j.jobe.2018.06.017.

Papadonikolaki, E. and Aibinu, A. (2017) 'The influence of leadership, resources and organisational structure on BIM adoption', in Proceedings of the 33rd Annual ARCOM Conference. Available at: http://www.arcom.ac.uk/abstracts-browse.php? $\mathrm{j}=2 \# 2$ (Accessed: 20 January 2020).

Pärn, E. A., Edwards, D. J. and Sing, M. C. P. (2018) 'Origins and probabilities of MEP and structural design clashes within a federated BIM model', Automation in Construction, 85, pp. 209-219. doi: 10.1016/j.autcon.2017.09.010.

Pope, C. and Mays, N. (2013) Qualitative Research in Health Care. 3rd Edition. Somerset: Wiley.

PwC (2018a) BIM Level 2 Benefits Measurement Introductory note: Approach and benefits framework. Available at:

https://www.cdbb.cam.ac.uk/files/2._pwc_introductory_note_to_bmm.pdf (Accessed: 9 February 2020).

PwC (2018b) BIM Level 2 Benefits Measurement Methodology. PricewaterhouseCoopers. Available at: https://www.cdbb.cam.ac.uk/files/3._pwc_benefits_measurement_methodology.pdf (Accessed: 20 January 2020).

Riley, D. and Horman, M. (2001) 'The Effects of Design Coordination on Project Uncertainty.', in Proceedings of the 9th Annual Conference of the International Group for Lean Construction (IGLC-9).

Riley, D. R. et al. (2005) 'Benefit-Cost Metrics for Design Coordination of Mechanical, Electrical, and Plumbing Systems in Multistory Buildings', Journal of Construction Engineering and Management, 131(8), pp. 877-889. doi: 10.1061/(ASCE)0733-9364(2005)131:8(877).

Sacks, R. (2016) 'What constitutes good production flow in construction?', Construction Management and Economics, 34(9), pp. 641-656. doi: 10.1080/01446193.2016.1200733.

Sacks, R. et al. (2018) BIM Handbook: A Guide to Building Information Modeling for Owners, Designers, Engineers, Contractors, and Facility Managers. 3rd edition. Hoboken, New Jersey: John Wiley \& Sons.

Saluja, C. (2009) 'A Process Mapping Procedure for Planning Building Information Modeling (BIM) Execution on a Building Construction Project'. Available at: https://etda.libraries.psu.edu/catalog/9848 (Accessed: 27 February 2020).

Seo, J.-H. et al. (2012) 'Collaborative process to facilitate BIM-based clash detection tasks for enhancing constructability', Journal of the Korea Institute of Building Construction, 12(3), pp. 299-314.

Staub-French, S. and Khanzode, A. (2007) '3D and 4D modeling for design and construction coordination: issues and lessons learned', Journal of Information Technology in Construction (ITcon), 12(26), pp. 381-407. 
Tan, T. et al. (2019) 'Barriers to Building Information Modeling (BIM) implementation in China's prefabricated construction: An interpretive structural modeling (ISM) approach', Journal of Cleaner Production, 219, pp. 949-959. doi: 10.1016/j.jclepro.2019.02.141.

Tommelein, I. D. and Gholami, S. (2012) 'Root causes of clashes in building information models', in Proceedings for the 20th Annual Conference of the International Group for Lean Construction. IGLC San Diego, LA, p. 10.

Van der Vlist, A. J., Vrolijk, M. H. and Dewulf, G. P. M. R. (2014) 'On information and communication technology and production cost in construction industry: evidence from the Netherlands', Construction Management and Economics, 32(6), pp. 641-651. doi: 10.1080/01446193.2014.911932.

Vass, S. and Gustavsson, T. K. (2017) 'Challenges when implementing BIM for industry change’, Construction Management and Economics, 35(10), pp. 597-610. doi: 10.1080/01446193.2017.1314519.

Wang, L. (2014) Knowledge formalization and reuse in BIM-based mechanical, electrical and plumbing design coordination in new construction projects using data mining techniques. Thesis. Available at: https://repositories.lib.utexas.edu/handle/2152/28692 (Accessed: 21 October 2019).

Wang, L. and Leite, F. (2016) 'Formalized knowledge representation for spatial conflict coordination of mechanical, electrical and plumbing (MEP) systems in new building projects', Automation in Construction, 64, pp. 20-26. doi: 10.1016/j.autcon.2015.12.020.

Yin, R. K. (2009) Case Study Research: Design and Methods. 4th Edition. SAGE.

Young, N. W. et al. (2009) The business value of BIM-getting building information modeling to the bottom line. McGraw Hill Construction SmartMarket Report.

Zhang, X. et al. (2018) 'Using Building Information Modelling to achieve Lean principles by improving efficiency of work teams', International Journal of Construction Management, 18(4), pp. 293-300. doi: 10.1080/15623599.2017.1382083. 